\title{
8. How IS design can contribute to a major climate change mitigation project
}

\author{
WALTER FERNÁNDEZ \\ AUSTRALIAN NATIONAL UNIVERSITY \\ BIRGITTA BERGVALL-KÅREBORN \\ LULEÅ UNIVERSITY OF TECHNOLOGY
}

MICHAEL DJORDJEVIC

KEITH LOVEGROVE

JAVIER FERNÁNDEZ-VELASCO

MISHKA TALENT

AUSTRALIAN NATIONAL UNIVERSITY

\section{Abstract}

Around the planet, numerous research initiatives are taking place to mitigate the effects of climate change. These activities - emerging from diverse research projects from basic and applied science - often suffer from lack of an overall design strategy that would allow capitalising on cross-specialised knowledge by having an integrative, holistic and synergistic approach to innovation design and implementation. This chapter discusses a particular research project and describes how a design methodology could help to address issues such as equality, empowerment, autonomy, creativity, performance and cycle times and provide for the necessary balance between control, speed and flexibility. 


\section{Introduction}

The societal awakening to the problems caused by climate change seems to be sudden, yet scientists have been working in their labs for years on different ways to alleviate this problem. At The Australian National University, for example, we are working on a program to establish new and sustainable carbonneutral energy sources that capitalises on Australia's natural advantages and know-how. Our project's ultimate objective is to develop a new oil industry to significantly reduce our dependency on fossil fuels. This aim will be achieved by producing a range of products, such as bio-fuels, without using food crops, destroying rainforests or arable land or competing with traditional agriculture for fresh water. ${ }^{1}$ This project could have national and international importance, yet we have struggled to define a project approach that is sensible, efficient and effective and also easy to communicate to decision makers and potential partners.

In this chapter, we describe some of the general aspects of this initiative and suggest a way in which potential synergies can be achieved. The chapter presents our problem and current state of ideas with the aim of generating discussion that could result in more substantial research and practical outcomes. We are interested not so much in being right as in developing useful and enabling knowledge from a given starting point. To attain the chapter's goal, we will depart from the traditional form of presenting the literature review at the beginning of the chapter. Rather, we will address the literature after describing the problem domain and the knowledge emerging from our project. The following description of the project is critical to situate this chapter's central discussion.

\section{The BioSolar project}

The embryonic idea for this project was born out of research work on oilextraction methods from micro-algae conducted at The Australian National University by Mishka Talent under the supervision of Keith Lovegrove and Javier Fernández-Velasco (Talent 2006). This section provides an overview of the problem domain and explains the basic concepts behind the project.

\footnotetext{
1 The term 'bio-fuel' refers to liquid, gas and solid fuels predominantly produced from biomass — such as: bio-ethanol, bio-methanol, vegetable oils, bio-diesel, biogas, bio-synthetic gas (bio-syngas), bio-oil, FischerTropsch liquids and bio-hydrogen (Demirbas 2008).
} 


\section{The problem domain}

We depend on petroleum products to fuel our cars, to warm our homes and to provide petroleum-based components for plastics, medicines, food items and a host of other products. The continued use of fossil fuels as an energy source is, however, having adverse effects on the environment and alternative sources are urgently required (Witze 2007). Simultaneously, worldwide concerns about global warming, climate change and pollution have sharpened public demand for sustainable energy solutions. Thus, a considerable effort is required to find and deploy sustainable solutions without derailing economies or sacrificing modern lifestyles. One of these potential solutions can be found in the innovative use of solar energy.

Several technologies have been developed to capture solar energy, including the harvesting of sunlight as plant biomass in a variety of 'energy' crops. The International Energy Agency (IEA 2004) raises doubts, however, over the economic viability of current bio-fuels. Furthermore, feedstocks such as corn, sugar, soya beans and wheat are perceived as critical food sources for an increasing world population. Arable land is required for growing food crops that can be utilised for oil production (Demirbas 2008) and the diversion of food crops to energy production is one of the alleged reasons for spikes in food prices.

In contrast, marine micro-algae can be grown without competing for fresh water or arable land used in classical agriculture. Research shows that selected micro-algae (single-celled plants and bacteria) can photosynthetically generate biomass, protein, oil and other feedstocks potentially with productivities much higher than the best traditional crops (Chisti 2008).

Micro-algae can grow in seawater or wastewater that is unsuitable for other purposes (Chisti 2007). Micro-algae can utilise carbon dioxide $\left(\mathrm{CO}_{2}\right)$ and other greenhouse gases generated by fossil-fuel combustion and, through biotechnology, we can manipulate micro-algae to generate new feedstock sources for pharmaceutical and chemical industries.

We are currently at the problem definition phase and are trying to plan the activities required and the resources needed to develop sustainable industries based on combining micro-algal cultivation and solar-thermal technologies. Sub-projects that combine these two technologies can result in the production of bio-fuels such as bio-diesel, hydrogen, ethanol, methane and also new feedstock sources for other industries. Recognising that the scope of the project goes beyond the technical and scientific components, the project is receiving 
contributions from the fields of project management and information systems (IS), making it a cross-campus initiative. We call this broad and evolving initiative the BioSolar project.

\section{Basic concepts behind the BioSolar project}

The BioSolar project aims to provide a blueprint for sustainable, carbon-neutral and efficient production of fluid fuels for Australian and international markets. To achieve this objective, we need to combine best-of-breed micro-algal and solar-thermal technologies while remaining open to complementary technologies that could be coupled to the system.

Micro-algae represent an untapped and versatile cropping system. Selected micro-algae can photosynthetically generate biomass, oil, protein and other industrial feedstocks and, with effective carbon dioxide supplementation and non-limiting growth conditions, they can achieve this with productivities up to 10 times higher than the best traditional crops and forestry systems (Chisti 2007, 2008).

These micro-algae can industrially transform sunlight energy into bio-diesel or hydrogen - both sustainable sources of energy - and into other industrial feedstock. In addition, micro-algae can contribute to atmospheric carbon dioxide abatement-indirectly, by minimising the need for fossil fuels, and directly, by acting as net carbon sequesters. Net carbon sequestration can occur by converting the biomass to char through a process called pyrolysis (Lehmann 2007). The carbon captured in the char is stable for long periods and the application of char to crops is reported to lead to increases in crop biomass.

Solar-thermal technology collects sunlight energy as heat for industrial use, including the generation of electricity and superheated water (Lovegrove et al. 2004). The BioSolar production plants could utilise highly efficient solar-thermal technologies to provide all the energy required for the industrial processing of the micro-algae. Because the selected solar-thermal technology can provide all the electrical and heat power needed to operate the full industrial plant, it is possible to efficiently generate carbon-neutral sustainable energy and a set of products for agriculture and other industries.

Marine micro-algae offer the simplicity of biological production systems common to all plants but with a number of significant advantages over traditional crops. During early discussions, we articulated a number of reasons why micro-algae could become the preferred new crop for most purposes where biomass is required; this initial set included adaptability, productivity, industrialisation and ecological impact. 
The science involved in solar-thermal and micro-algae technologies is well advanced and offers great potential for further improvement. By coupling biomass generation via micro-algal photosynthesis to solar-thermal technologies, a variety of products can be obtained, ranging from human and animal foods to substances of energetic or medical importance. These include: aviation fuel, biodiesel, plastics, biogas, ethanol, pharmaceuticals, neutraceuticals, antibiotics, bioremediation, sewage treatment, animal feed, soil conditioner and net carbon dioxide sequestration. Solar-thermal concentrators such as The Australian National University's Big Dish system can produce temperatures high enough to drive thermo-chemical reactions. In particular, biomass and water mixtures can be processed to produce carbon monoxide and hydrogen mixtures that are the basic feedstocks for processes producing a range of liquid fuels. In doing so, the solar concentrator is adding to the energy stored in the biomass and simultaneously processing it into a more useful form. A key hypothesis behind the BioSolar project is that combining algae with solar-thermal technology into an integrated and optimised system will give a result that is better economically than either technology on its own. The BioSolar project aims to successfully combine these technologies, producing a market-ready solution to a unique and pressing problem. To deploy an effective commercial solution, however, far more needs to be accomplished, and this is discussed next.

\section{The blank slate and the green field}

With the 1970s and 1980s oil crises over, research funds into algal-based biofuels practically disappeared. The scientific knowledge is, however, available and ready to be reactivated. In terms of biological science, we are starting from a solid base and with proven technology. The key challenge, however, remains in the industrialisation and commercialisation aspects of this technology. We need to take the production of oil from the controlled environment of the laboratory's bench to the industrial and commercial environment, and this task is too complex and too urgent to be left to chance.

To achieve the transformation from laboratory bench to product delivery, we have to confront a number of important issues - including, but not limited to: scalability; automation; business process analysis and design; management of development activities; integration and coordination of multiple concurrent projects; skill development for scientists, engineers and technical personnel; design and development of information systems, information technology (IT) and special equipment; automation and remote management systems; identification of complementary algal technologies; environmental accounting assessments; development of replicable and adaptable production protocols; and implementing effective supply chains. 
We have a green field in front of us. This is a significant challenge, as many minds, from many fields, with different world views and agendas, will need to work in a coordinated manner, addressing priorities and developing a long-term plan of action that is efficient, effective and flexible enough to accommodate the uncertainties of innovative endeavours. Without planning, the many activities will grow organically - some to success, others to failure. Yet we are facing a problem that forces us to respond in a short time and with the minimum of waste. Thus, the option for unplanned or isolated evolution seems, at best, risky.

The overall planning for this major project is, however, a difficult and complex task because our knowledge of the problem domain is far from perfect and its context is plagued with uncertainties. Consequently, the planning tools need to be flexible and evolutionary, adopting a performing view of project knowledge in which knowledge is regarded 'not as static or given, but as a capability produced and reproduced in recurrent social practices' (Orlikovski 2006:460).

We need an effective way of designing a new industry in a manner that is incremental in nature and facilitates the end-to-end efficient and effective management of the project - from conceptual design to prototype design and to product and services design. The elements to be designed and implemented in this project are many, including, among others, engineering, biotechnology, commerce, manufacturing, training, regulatory frameworks, partnerships and information systems. Further, the techno-centric approach seems to be limited, as we need to develop the technology in a social and political context, taking into consideration demands from business, government and academic stakeholders, among others.

To successfully design and implement the socio-technical innovation, a suitable methodology must include human and technical aspects and work across complementary fields. This approach needs to act as a scaffold for the generation of knowledge and physical artefacts. Orlikovski (2006) describes the notion of scaffolding as a useful metaphor for studies of performative knowledge. Certain elements of scaffolding, with regard to human agency, can be useful to our project. We are attracted to the notion that scaffolding can extend, complement, link, stabilise, reconfigure and transform human agency (Orlikovski 2006). The next section describes a method that has been successfully used in Europe to manage innovative projects and that appears promising in addressing our significant challenges. 


\section{FormIT: designing complex and innovative systems}

During the initial planning stage of the BioSolar project, we understood that to succeed we needed to produce a system that considered the human aspect of the technology in order to enhance the effectiveness and implementation of the technology. Some guidance for this kind of design can be found in the ISO 13407:1999 human-centred design process for interactive systems. This international standard describes aspects of software and hardware systems so project managers can understand the basic issues involved when including human-centred activities throughout a development life cycle, but it does not cover all aspects of project management. It also does not cover in detail the practical issues of conducting human-centred design or the necessary methods and techniques.

The starting point to manage projects such as BioSolar can be found in FormIT (Bergvall-Kåreborn et al. 2007; Ståhlbröst and Bergvall-Kåreborn 2007a) —an approach originally created for developing IT-based artefacts and services that takes a 'human-centred' (Kling and Star 1998) approach to design. FormIT aims to guide and facilitate the development of innovative services that are based on a holistic understanding of people and their behaviour, grounded in needs and wants that stakeholders experience as relevant. FormIT takes seriously issues such as equality, empowerment, autonomy and control in relation to real use situations - that is, including the whole system in development and in operation. These issues are critical to achieve the collaboration necessary for the project to work in a synergistic manner, having the necessary flexibility to enhance creativity and innovation and the critical controls to ensure that we advance in a coordinated and planned manner.

FormIT is inspired by three theoretical streams: soft systems thinking (SST), appreciative inquiry and need finding. From SST (Checkland and Holwell 1998; Checkland and Scholes 1999), FormIT borrows the assumption that changes can occur only through changes in mental models. This implies that we need to understand our own as well as other stakeholders' world views and we need to be clear about our interpretations and the base on which they are made (BergvallKåreborn and Ståhlbröst 2007; Ståhlbröst and Bergvall-Kåreborn 2007b). Hence, we aim to interpret and understand situations through an iterative and interactive process with stakeholders. This concept fits well with the principles stated in the BioSolar project since we strongly believe that complex systems with multiple stakeholders cannot be successfully developed in the isolation of the laboratory's bench. We also need to define what success means to the project; this definition is a social construction that facilitates the project's outcome (Thomas and Fernández 2008). 
Appreciative inquiry (Cooperrider and Avital 2004; Cooperrider and Whitney 2005; Cooperrider et al. 2005; Norum 2001) has encouraged the Swedish author(s) to start the development cycle by identifying different stakeholders' dreams and visions of how technology can improve and support the lives of people. This includes a focus on opportunities related to specific trends, contexts or stakeholder groups and on the positive and life-generating experiences of people. This way of thinking is closely aligned with the philosophy behind SST since it also highlights the importance of people's thoughts about themselves and the world around them in design situations. Hence, instead of starting the process by searching for problems to solve in a situation, we identify what works well and use this as a basis for design. In the BioSolar project, we have identified technologies that work well (algal technologies and solar thermal) as the starting point for our design.

Need finding (Bergvall-Kåreborn et al. 2007) is about focusing on stakeholders' needs throughout the development process and using these as a foundation for requirement specification. Patnaik and Becker (1999) state that the main motivator for the need-finding approach is that needs are not highly influenced by trends-hence, they are more long lasting. Therefore, the project must include and provide adequate resources for the needs-elicitation process (Kankainen and Oulasvirta 2003; Kankainen et al. 2003; Tiitta 2003). In our perspective, identifying opportunities is the basis for appreciating needs since needs are opportunities waiting to be exploited.

FormIT also strongly emphasises the importance of the first phase in the development cycle - usually referred to as analysis or requirements engineering. Since this phase creates the foundation for the rest of the process, errors here become very hard and expensive to correct in later stages. Following the human-centric approach, this is also the phase where stakeholders make the strongest contribution by really setting the direction for the design, rather than responding to half-finished prototypes. Since stakeholder needs and requirements can change as they gain more knowledge and insight into possible solutions, it is important, however, to continually reassess these needs and to ensure that needs correlate to given requirements.

In conclusion, FormIT is an iterative method in which continuous interaction with stakeholders is an understood prerequisite. The basic idea is that knowledge increases through iterative interactions between phases and people with diverse competencies and perspectives. In this way, knowledge increases through dialogue between participants (Ståhlbröst and Holst 2006). The cross-functional interaction enables the processes of taking knowledge from one field to another to gain fresh insights, which then facilitates innovative ideas. The shared understanding of the situation informs and enriches the learning processes and thus facilitates changes in perspective and leads towards innovative design 
processes (Holst and Mirijamdotter 2006). This, in turn, increases our ability to design systems that answer to stakeholder needs. A more detailed description of the method follows.

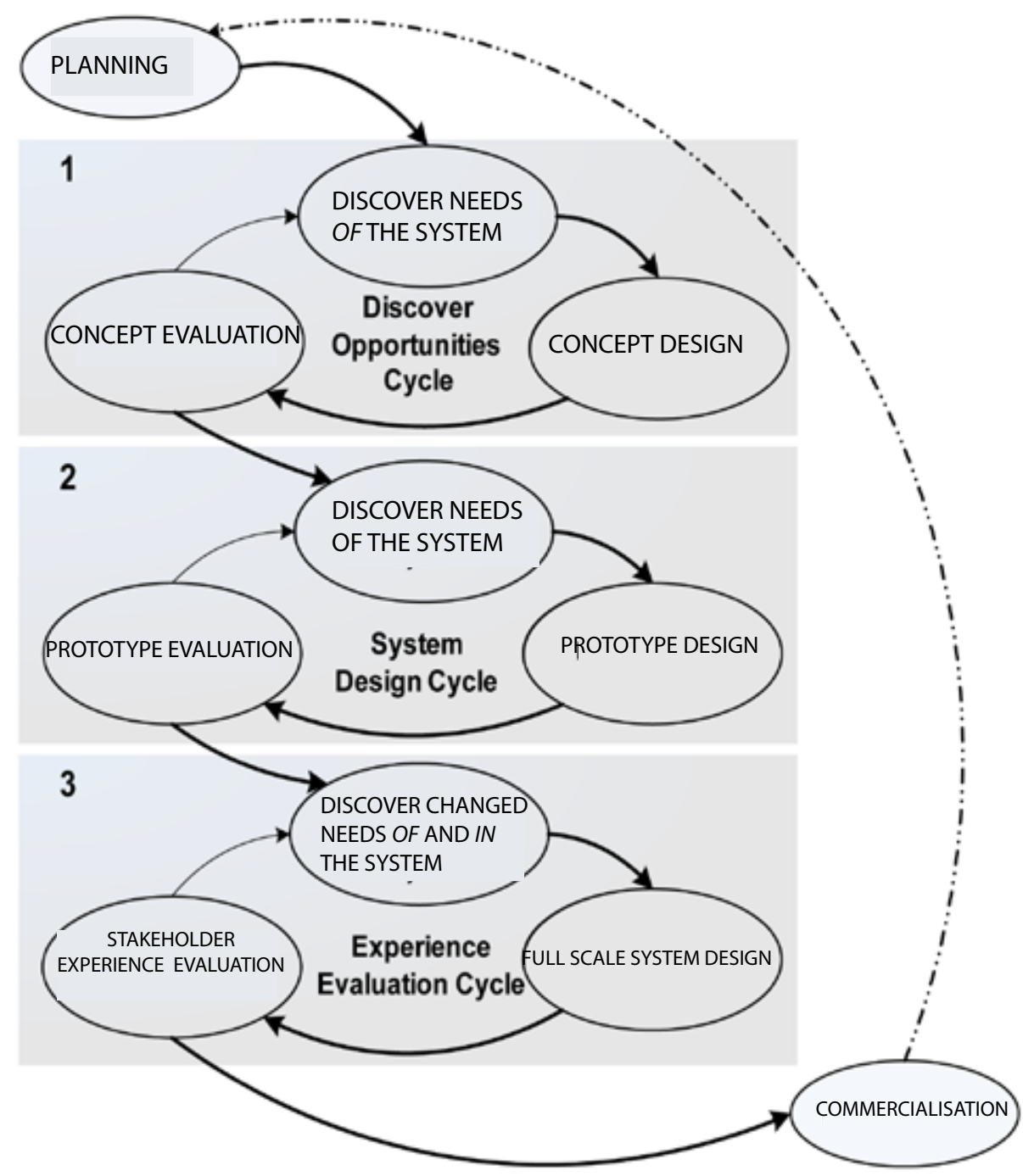

Figure 8.1 The FormIT process for innovation development

\section{The FormIT method}

FormIT can be seen as three interconnected evolutionary cycles (discover opportunities, system design and experience evaluation) in which the design becomes increasingly clear, while the attention of the evaluation broadens from a focus on concepts and prototype to a holistic view of the use of the system. 
Within each of the cycles three basic phases are repeated (discover needs, design and evaluate). The full methodology includes two additional phases (planning and commercialisation), as seen in Figure 8.1.

Planning stands for planning the intervention as a whole and here it is important to gain as much information as possible about the underlying circumstances for the project: its aim and scope, different perspectives on the project and constraints and boundaries that need to be accepted. Three important perspectives that need to be considered and combined are the human, technological and business perspectives of a project. It is common that different stakeholders assign different priorities to each of these perspectives. There is nothing wrong with this as long as everyone understands the importance of all three perspectives and how they contribute to, and interact with, each other.

While planning the intervention can be seen as the start-up phase of the project as a whole, many of the guidelines and lessons learned in relation to this phase can also be applicable in the planning of the subsequent phases. In a large, complex and multidisciplinary project such as the one described in this chapter, the planning phase is extremely important since divergent views on the aim and scope of the project - as well as on roles, responsibilities and authoritycan put the whole project at risk. Hence, before leaving this phase, a sense of 'accommodation' (Checkland and Scholes 1999) concerning these issues needs to be reached between key stakeholders.

The commercialisation work needs to be integrated into the development work but is often treated as a separate project in which the aim is to implement the system and to introduce it to the market. While the commercialisation effort and focus are greater nearing project completion, this phase is definitely not a passive sink collecting the results of previous cycles. We acknowledge that system design cycles inform commercialisation and are also informed by commercialisation issues. This is critical to facilitate effective end-to-end alignment. Also, lessons learned from commercialisation experiences inform the planning of future systems. As this chapter focuses on the planning phase and the subsequent design cycles, the commercialisation phase is mentioned here for completeness purposes only.

Before discussing the steps required for the BioSolar project, the following subsections provide a short description of the character and main activities of each one of the three cycles.

\section{The first cycle: needs of}

The first cycle focuses on discovering the basic needs that different stakeholders have of the system. These are the needs that motivate them to buy and use a particular product or service. Following the language of soft systems 
methodology, these needs are part of the 'weltanschauung' (Checkland and Davies 1986) - the world view that makes the service meaningful to use. The needs of the system can vary and take different forms depending on stakeholder, context and situation. The challenge in the discovery phase of the first cycle is thus to identify the key needs of the system and the different expressions they might take. This is done by obtaining a rich picture of different stakeholders, their behaviour, attitudes and values. When this is achieved, the needs are translated into design concepts in the form of scenarios or mock-ups. By doing this, the focus shifts from the discovery phase to the design phase. The aim of the design phase is to develop new and innovative concepts based on the data from the discovery phase. The concepts need to be detailed enough for the stakeholders to understand the basic objective and functions of the system. From here, the focus shifts again - this time from the design phase to the evaluation phase. The aim of the evaluation of the first cycle is to make sure that the stakeholders agree with the basic objectives of the developed concepts. This means relating the basic objectives and functions of the system to the identified needs of the system, making sure that these are consistent. If they are not, this cycle needs to be repeated until such coherence is achieved.

\section{The second cycle: needs in}

The second cycle starts with the process of identifying stakeholders' needs in the system. That is, what needs in the finished system are important for stakeholders. As in the first cycle, this is done through a variety of data-gathering methods such as interviews and observations. The challenge in this second cycle is to separate needs of the system (visions and motivations) and needs in the system (goals, processes and functions). One way of doing this is to keep the concept design - with key needs related to it - visible for the stakeholders during the data-collection activities so it is possible to relate to these during the discussions. When the data collection no longer generates new insights and findings, we consider that we have reached saturation and the focus again shifts to the design phase. In the second cycle, however, the design of the system broadens to include basic functions, workflows and interfaces. The prototype or design needs to be detailed enough for the stakeholders to understand and be able to experience how the final system will look and feel. This leads us to the evaluation, which is centred on structure, processes, activities and information flows in the second cycle. It includes questions and analyses concerning how different subsystems need to be integrated and how they affect each other and the system as a whole. The evaluation is focused on the interaction between the parts and the whole. 
The third cycle: needs of and in

The third cycle starts by analysing the results from the prototype evaluation in order to discover changes in the needs of and in the system. Small changes and adjustments in the needs are quite common, especially in relation to the needs in the system, as the system develops and stakeholders' understanding of structure, content, workflow and interface deepens. Based on these changes, alterations in the design of the system also take place, as well as in the general development work to finalise the system as a whole. When this is done, the last evaluation phase takes place and now the evaluation is focused on the relation between the system and its users. Stakeholder experiences and goals are primarily subjective qualities and concern how a system feels to a stakeholder. They differ from more objective performance goals in that they are concerned with how stakeholders experience the system and its performance and how useful they consider the system to be, rather than assessing how efficient or productive a system is.

\section{Using FormIT in the BioSolar project}

As discussed above, each critical cycle is divided into three phases that iterate until the cycle is successfully completed. This section briefly describes a number of recommended actions and the state of our knowledge regarding potential activities to be conducted in future interventions in the BioSolar project.

\section{Initial planning of the BioSolar project}

We have found that, as in every project, it is highly important to gain a common perspective of the main purpose of the project (Ståhlbröst et al. 2005). This can be difficult to accomplish since project participants usually want to make contributions to many different areas. In large, complex and multidisciplinary projects, as with the BioSolar project, this is particularly challenging since it can be hard for participants to grasp the project as a whole, as well as to fully understand the more detailed work tasks of stakeholders from other disciplines. It is therefore important to support a communicative approach that builds trust and confidence between the stakeholders (Ståhlbröst 2006) and to find ways of illustrating how the different parts of the project relate to each other. For this, we could adopt PAWDAC (Bergvall-Kåreborn et al. 2004) or critical systems heuristic's boundary questions (Bergvall-Kåreborn 2006; Ulrich 1987, 1998). For example, using PAWDAC would involve discussing and reaching consensus related to the following questions. 
- Process: what is the key process to be carried out in the project? What are the main sub-processes and their relationships? What is the time frame of the project and critical milestones?

- Affectees: who are the beneficiaries and victims of the project?

- Weltanschauung: what is the motivation of the project, as well as its purposes and goals? What is the problem or opportunity that the project aims to contribute to and the background and needs that formed the project idea?

- Decision maker: identify those with authority and responsibility over the project and with prime concern for its performance. Any power relations that are of importance to the project should also be considered, along with consideration of how these could have influence on the intervention.

- Actors and other resources needed: what competencies and resources are important to the process? What technology does the project require? Does this technology exist today or will it be developed within the project?

- Boundaries and constraints: what in the context might influence the intervention and what in the intervention might influence the context?

When these questions have been discussed and agreed on, the first phase of the FormIT process - the discover needs phase - can start.

\section{Phase one in each cycle: discovering the needs of the BioSolar system}

This phase is repeated in all three cycles. In the first cycle, it is called discover needs of; in the second cycle, it is called discover needs in; and in the third cycle, it is called discover needs of and in (as in Figure 8.1) - but the focus is slightly different in the different cycles. In the first cycle, the aim is to gain insight into the different basic needs that different stakeholders have of the BioSolar system.

To do this, we plan to use a mixture of data-collection methods, including focus-group interviews, individual interviews, storytelling, observations and formal documents. In both focus-group interviews and the individual interviews, we will ask the participants to tell stories that reveal their views on their present and future situations and how the BioSolar system will help them to make this transformation. These stories will include stories based on their positive experiences related to their everyday situation and technology usage. Focusing on past, present and future situations instead of present problems and existing technological solutions is important to generate a positive and creative atmosphere in the group. This atmosphere, combined with the focusgroup interview technique, stimulates the stakeholders to generate innovative ideas and visions together in a conversational mode. In these conversations, users become inspired-hence, they stimulate each other to go beyond their 
own frame of mind by developing ideas generated by others. This produces a fruitful and interesting snowball effect, which helps all group members to participate actively during the discussion. In the first cycle, we plan to have more heterogeneous and non-established groups since this creates understanding and knowledge sharing between existing groups and subjects within the project. It also allows for different views and ideas to cross-fertilise and creates new and innovative ideas. In the second cycle, we will use more homogenous and established groups since this facilitates the discussion of in-depth questions within a field or subject.

Since it sometimes can be complicated to encourage participants to tell rich stories in the mode and depth that are needed for eliciting needs in group discussion, we will also use individual interviews in order to focus on and excavate specific issues or stories expressed by single participants in the group interviews. To focus on one single participant in a group interview might lead to the feeling among the other participants of not being fully included. In addition, focusing on one person's story and digging into that can result in a feeling of being singled out in front of the other participants. Individual interviews will also be used when the area of concern is of sensitive character, such as confidential information that might be of value for the project.

Our experience is that appreciating strengths and dreaming of the future are difficult for most people because they are stuck in present problems and in their picture of currently existing technological possibilities. To stimulate this 'shift to the future', we will use scenarios as stimuli in two different ways: we will present scenarios for the stakeholders in order to help participants get started in their process and we will ask them to describe a scenario to us.

The usage of stimulus material, such as scenarios or mock-ups, needs to be considered in depth. We have found that stimulus material can have a noticeable impact on the topics being addressed in the groups. The stimulus material can smooth the progress of the discussions and we have also used it to fuel discussions when they have started to diminish. In these situations, the material can boost the discussions and the focus-group participants' imaginations. Hence, the respondents become aware of new needs and more possible solutions than they had been aware of previously. The usage of stimulus material is, however, not risk free. It can also steer the discussion away from revealing the critical needs of the stakeholders. Thus, to carefully consider and try to imagine the impact of the stimuli are of utmost importance if a high level of validity is desired in the study. 
In addition, our experience in Sweden shows that it is necessary to have a blend of competence among the moderators facilitating the interviews since respondents sometimes ask important questions about a certain technology that need to be understood for the discussion to develop.

\section{Phase two in each iteration/cycle: design the BioSolar system}

The aim of this phase is to design and develop innovative concepts on the basis of the identified needs from the earlier phase. The design phase is also carried out in all three iterations. In the first iteration, it is called concept design; in the second, prototype design; and in the third, it is called full-scale system design (as in Figure 8.1). So far, we have focused on the conceptual design that is part of the first cycle of the FormIT process and the cooperation between different stakeholders to ensure that knowledge is shared both across and within competence areas.

Based on our research, we have found that to ensure that the final solution answers stakeholders' needs, and does not merely reflect what is technically possible, a close interaction between stakeholders representing the human, technical and business perspectives is needed. This does not mean, however, that all stakeholders need to be involved in all the stages of development; rather cooperation should build on mutual communication around these perspectives when designing the system. The objective is to ensure that the knowledge gained from earlier stages is guaranteed to be included and considered in the final design.

In this phase, the known needs as well as identified strengths and dreams form the basis for the vision of the system that takes shape here. Usually a basic idea of the future solution has started to take form - hence, the idea will be elaborated on and expressed textually, in the form of key concepts, and pictorially, in the form of user stories, scenarios or mock-ups of the system. Broadly speaking, there are two types of design: conceptual and physical. Conceptual design is concerned with developing models that capture what the product will do and how it will behave, while physical design is concerned with details of design such as chemical processes, innovative use of solar-thermal energy, work flows or security systems.

In the BioSolar project, many different concepts need to be designed, representing everything from methods of growing the micro-algae and developing it into different products to information systems that facilitate and control these processes, as well as managing the project as a whole and the production site once the project is implemented. All these concepts then need to be clustered 
and discussed in order to generate new, innovative solutions by relating diverse concepts together, but also to understand how the different key concepts fit together into a meta-model. From the selected concepts, requirements are generated and from the requirements the first prototypes are designed and refined. Through the design phases, it will be important to continuously assess the design outcomes against the needs representations from the previous phase.

We have found in previous projects that in order to communicate the idea of a product or service, different types of visualisations are very powerful. In the BioSolar project, we will therefore use a number of methods, including

- storyboarding - a series of drawings that shows how the user might progress through a task using the intended design

- scenarios - an informal story description that describes the tasks the user will undertake when s/he uses the design; these stories will be closely related to the stakeholder's contexts and expected behaviours; further, they will be related to the goal, or needs, that the stakeholder has expressed

- use cases - a representation that focuses on the interaction between the stakeholder and the system rather than specific user tasks; the use case scenario represents one possible path of behaviour

- essential use cases - a combination of use cases and scenarios; this is a structured story consisting of user action and a step-by-step description of the responsibility of the system

- paper prototypes, mock-ups and card-based prototypes - ways to design the system and present it in sketches in which each sketch can represent a screen or a view of the system.

As the process iterates through the model, the key concepts and pictorial expressions of the system will be developed into prototypes and, later, a finished system. The challenge here is to convince the system developers and technical engineers to consider the list of prioritised needs as a starting point for the vision and then the functional requirements and technical specifications. Since many developers and engineers are unfamiliar with this way of working, they often want to skip this part and go directly to the requirements and specifications.

\section{Phase three in each cycle: evaluation of the BioSolar system}

As with the previously described phases, this phase is carried out in all three cycles. It is called concept evaluation in the first cycle, prototype evaluation in the second and in the third it is called stakeholder experience evaluation (see Figure 8.1). The goal of this phase is to produce a thorough evaluation of the system 
to determine if further iterations are required within a particular cycle before proceeding to the next cycle (or to commercialisation in the case of the third cycle).

In this phase, stakeholders are encouraged to give their impressions of the system that has been developed, based on stated needs. At this point, the system can have different forms depending on where in the development process the system is. In the first cycle, the initial evaluation process completes the first iteration of the cycle by evaluating system concepts, or ideas, in relation to the discovered needs. Yet this is not just a simple verification exercise; the evaluation also aims to identify new and unexplored needs or modifications of needs. When these evaluations and investigations do not give any new insights regarding stakeholders' needs of the service, the next cycle can start.

In the second cycle, the focus is on evaluating a prototype of the system related to stakeholder needs in the system. Hence, the focus is on relationships between parts of the system and the system as a whole, concerning aspects such as processes, structures, activities and information flows. Also in this phase, the process is iterated until no new insights are identified.

The third cycle focuses on combining users' needs of and in the system and then it is developed into a full-scale system. Here the focus is on how the system really works and fits its context of use. For the development project to be successful, ownership of the system must be handed over to and accepted by the involved stakeholders. In this process, the participants might need to change their traditional way of working and acting because long-lasting and substantial change could have occurred. Thus, we need to consider process change management requirements as one of the deliverables of the design process.

Based on our experiences from working in IT innovation projects, we have found that determining what methods to use when evaluating innovative systems can be complicated. One aspect to consider here is the characteristics of the system or subsystem. Since the BioSolar system consists of many different subsystems of chemical, technological, ecological, economic, business and social natures, the system needs to be evaluated both on an overall level, covering all aspects, and on a subsystem level, with particular focus on the aspects governing a specific subsystem. Also, aspects such as whether the system or subsystem under consideration is a product or a service will affect the evaluation and its criteria. 
The evaluation process enables discussion among stakeholders as to how the concepts, prototypes or final solution can be related and refined to answer the needs identified in the earlier phases. Hence, the issues that need to be dealt with are

- what is the approach and purpose for the evaluation

- what is the main question that needs to be answered

- should the evaluation be of summative, formative or interactive character

- what kind of data are expected from the evaluation-qualitative or quantitative

- define what methods to use in the evaluation-interviews, logs, surveys, observations in relation to the purpose

- study the context to determine what, in the context, can influence the evaluation results

- create questions, observation schemas or other preconditions for the evaluation; at this stage, develop questions on the basis of the identified needs and requirements

- define the number of stakeholders and stakeholder groups and selection criteria such as age, gender, occupation, and so forth

- define what the characteristics of the innovation are; identify important 'has to' in the evaluation - such as when the test has to be done, the duration of the test, the character of the interaction, what a natural behaviour around the innovation is, degree of participation and so forth.

To sum up, the focus for this stage varies depending on where the innovation is in the development process. In the first cycle, the focus is on elaborating, with stakeholder needs of the system, while in the second cycle the focus is on the prototype and stakeholders' needs in the system. In the last cycle, we focus on user experiences and here the main aspect is to hand over the system to the various stakeholders and to ensure that all important roles, responsibilities and authorities needed to run the system have been defined and handed out. The objective here is to gain insight into stakeholders' needs of the system combined with their needs in the system.

\section{Conclusion}

In this chapter, we have presented a continuing project, providing a glimpse of the complexity involved. We propose that collaborative projects with multiple stakeholders and different world views require careful management. We have also argued that in managing projects in which significant collaborative 
innovations must be deployed, managers must pay special heed to the human aspects of the project in addition to the technical aspects. In this way, we do not perceive a dichotomy between technical and social considerations, but rather a natural integration of these aspects.

Hence, we need a methodology that allows for flexibility and that fosters creativity and understanding among stakeholders. We believe that a successful design methodology must provide the basic elements and processes necessary to produce the system in an efficient and effective manner. We believe that FormIT - a methodology used successfully to develop IT innovations - appears suitable for the BioSolar project. FormIT seems able to handle some of the identified problems and to provide the basis for further development of the innovation.

We have described the cycles in the process and given an example of potential techniques to elicit requirements, to facilitate and to verify the design. Furthermore, because the design method has a strong and coherent philosophical approach, we suggest that it can act as a guide to the overall project strategy, providing a system of belief appropriate for complex projects concerned with the development of innovative greenfield industries. The methodology is based on a holistic understanding of the problem domain and allows for evolution and flexibility while keeping the project grounded in the needs and wants of key stakeholders.

Our chapter is limited, however, in that it does not include a discussion of competing design approaches or a review of the innovation literature; it does not address the lack of a defined research question or problem or provide a discussion of academic politics and its role in the development of science and industry. In addition, we have taken a different approach to present our argument - a risky strategy not advisable for more formal research outlets but one that we believe is necessary at this stage. Perhaps the least clear aspect of this chapter is its contribution to knowledge. A reviewer suggested that possible contributions might be in the areas of complex systems development, project and program management, design science or alternative energy. These contributions are, however, speculative, so we can only offer this chapter as an attempt to bring to the discussion table some of the challenges we are currently facing in this project. The chapter itself is a boundary object devised to focus the development of a shared vision of problems and solutions (Gasson 2006).

Finally, the adopted design method provides the general strategy for managing the project, but, as with any complex project, both the method and the project evolve in action (Fitzgerald et al. 2002; Latour 1987). We need to apply the method as a scaffold to build project knowledge and to allow for the efficient and effective progress of the project. FormIT was developed from a human- 
centric viewpoint that, taken to extremes, could negate the importance of the technology. How much we are going to be able to address this bias to reach a middle ground that takes into account both the technical and the human is debatable. We must insist, however, that our intention is not to stress the formality of the approach but rather its potential for flexibility and adaptability in use. We agree with Berg (1997:406) that

the idea of an intelligent or self-sufficient formal tool within the complexity of the informal/empirical is an anathema. By themselves, formal tools are utterly powerless...[and t] he formal is symbolic, clean, abstract, homogeneous; the empirical is messy, heterogeneous, concrete, and not [to be] ordered within one single scheme. The formal is the representation, the map; the empirical is the represented, the terrain.

Thus, we do not claim a perfect match nor do we claim that the work in methodology design has been completed. It will remain a work-in-progress as more ideas emerge and new activities need to be conducted to let the terrain shape the map that will in turn shape the terrain. Certainly, integrating FormIT into a general project management framework requires more empirical work. The conceptualisation of design cycles, however, the simplicity and consistency of the phases and our perceived compatibility with the philosophical approach offered by FormIT provide a good starting point for our project.

\section{References}

Berg, M. 1997, 'Of forms, containers, and the electronic medical record: some tools for a sociology of the formal', Science, Technology, \& Human Values, vol. 22, no. 4, pp. 403-433.

Bergvall-Kåreborn, B. 2006, 'Diversity is in the air-it is time to challenge our weltanscauung', Systemist, vol. 28, no. 2, pp. 13-25.

Bergvall-Kåreborn, B. and Ståhlbröst, A. 2007, 'The elusive nature of user needs in existing information systems literature', Proceedings of the 8th IBIMA Conference: Information management in the networked economy, Dublin, pp. 479-87.

Bergvall-Kåreborn, B., Holst, M. and Ståhlbröst, A. 2007, 'Creating a new leverage point for information systems development', in M. Avital, R. Boland and D. Cooperrider (eds), Advances in Appreciative Inquiry-Designing information and organisations with a positive lens, Elsevier, Amsterdam, pp. 75-95. 
Bergvall-Kåreborn, B., Mirijamdotter, A. and Basden, A. 2004, 'Basic principles of SSM modelling: an examination of CATWOE from a soft perspective', Systemic Practice and Action Research, vol. 17, no. 2, pp. 55-73.

Checkland, P. B. and Davies, L. 1986, 'The use of the term "weltanschauung" in soft systems methodology', Journal of Applied Systems Analysis, vol. 13, pp. 109-15.

Checkland, P. and Holwell, S. 1998, Information, Systems, and Information Systems: Making Sense of the Field, John Wiley \& Sons, Chichester, UK.

Checkland, P. B. and Scholes, J. 1999, Soft Systems Methodology in Action: A 30year retrospective, John Wiley \& Sons, Chichester, UK.

Chisti, Y. 2007, 'Biodiesel from microalgae', Biotechnology Advances, vol. 25, no. 3, pp. 294-306.

Chisti, Y. 2008, 'Biodiesel from microalgae beats bioethanol', Trends in Biotechnology, vol. 26, no. 3, pp. 126-31.

Cooperrider, D. L. and Avital, M. (eds) 2004, Advances in Appreciative Inquiry, Constructive Discourse and Human Organisation, Elsevier, Oxford.

Cooperrider, D. L. and Whitney, D. 2005, Appreciative Inquiry-A positive revolution in change, Berrett-Koehler Publishers, San Francisco.

Cooperrider, D. L., Whitney, D. and Stavros, J. M. 2005, Appreciative Inquiry Handbook, Berrett-Koehler Publishers, San Francisco.

Demirbas, A. 2008, 'Biofuels sources, biofuel policy, biofuel economy and global biofuel projections', Energy Conversion and Management, vol. 49, no. 8 (August), pp. 2106-16.

Fitzgerald, G. B., Russo, N. L. and Stoltermane, E. 2002, Information Systems Development: Methods-in-action, McGraw-Hill, Maidenhead, UK.

Gasson, S. 2006, 'A genealogical study of boundary-spanning IS design', European Journal of Information Systems: Special issue: action in language and organisations, vol. 15, no. 26 , p. 1.

Holst, M. and Mirijamdotter, A. 2006, 'Interaction in cross-functional team work: making sense through the POM model', Systems Research and Behavioural Science, vol. 18, pp. 323-333.

International Energy Agency (IEA) 2004, Biofuels for Transport: An international perspective, International Energy Agency, Paris. 
Kankainen, A. and Oulasvirta, A. 2003, 'Design ideas for everyday mobile and ubiquitous computing based on qualitative user data', in N. Carbonell and C. Stephanidis (eds), User Interfaces For All, Springer-Verlag, Berlin, pp. 458-64.

Kankainen, A., Tiitta, S. and Rantanen, M. 2003, 'Exploring everyday needs of teenagers related to context and presence aware mobile services', Proceedings of Human Factors in Telecommunications, pp. 19-26.

Kling, R. and Star, S. L. 1998, 'Human centered systems in the perspective of organizational and social informatics', Computers and Society, March, vol. 28, no. 1, pp. 22-29.

Latour, B. 1987, Science in Action: How to follow scientists and engineers through society, Harvard University Press, Cambridge, Mass.

Lehmann, J. 2007, 'A handful of carbon', Nature, vol. 447, pp. 143-4.

Lovegrove, K., Luzzi, A., Soldiani, I. and Kreetz, H. 2004, 'Developing ammonia based thermochemical energy storage for dish power plants', Solar Energy, vol. 76, nos 1-3 (January-March), pp. 331-7.

Norum, K. E. 2001, 'Appreciative design', Systems Research and Behavioral Science, vol. 18, pp. 323-33.

Orlikovski, W. J. 2006, 'Material knowing: the scaffolding of human knowledgeability', European Journal of Information Systems, vol. 15, pp. 460-6.

Patnaik, D. and Becker, R. 1999, 'Needfinding: the why and how of uncovering people's needs', Design Management Journal, vol. 10, no. 2, pp. 37-43.

Ståhlbröst, A. 2006, Human-Centric Evaluation of Innovation, Department of Business Administration and Social Sciences, Luleå University of Technology, Sweden.

Ståhlbröst, A. and Bergvall-Kåreborn, B. 2007a, 'FormIT - an approach to user involvement', in J. Schumacher and V.-P. Niitamo (eds), European Living Labs-A new approach for human centric regional innovation, Wissenschaftlicher Verlag Berlin Olaf Gaudig and Peter Veit GbR, Berlin, pp. 63-76.

Ståhlbröst, A. and Bergvall-Kåreborn, B. 2007b, Unveiling the mysterious needs of users, 30th Information Systems Research Seminar in Scandinavia, IRIS30, Department of Computer Sciences, University of Tampere, Finland. 
Ståhlbröst, A. and Holst, M. 2006, 'Appreciating needs for innovative IT design', International Journal of Knowledge, Culture and Change Management, vol. 6, no. 4, pp. 37-46.

Ståhlbröst, A., Mirijamdotter, A. and Bergvall-Kåreborn, B. 2005, 'Needs and accommodation in evaluation design', 12th European Conference on Information Technology Evaluation (ECITE 2005), Turku, Finland, pp. 45764.

Talent, M. 2006, 'A sustainable photosynthetically derived liquid fuel for developing countries: a simple method of extracting oil from microalgae', Engineering, The Australian National University, Canberra.

Thomas, G. and Fernández, W. 2008, 'Success in IT projects: a matter of definition?', International Journal of Project Management, vol. 27, no. 7, pp. 733-742.

Tiitta, S. 2003, 'Identifying elderly people's needs for communication and mobility', Include 2003, vol. 7 (March), pp. 266-71.

Ulrich, W. 1987, 'Critical heuristics of social systems design', European Journal of Operational Research, no. 31, pp. 276-83.

Ulrich, W. 1998, Systems thinking as if people mattered, Working Paper No. 23, Centre for Systems Research, Lincoln School of Management, University of Lincolnshire and Humberside, UK.

Witze, A. 2007, 'That's oil, folks...', Nature, vol. 445, pp. 14-17. 